\title{
Role of Nitric Oxide in Parasympathetic Modulation of $\beta$-Adrenergic Myocardial Contractility in Normal Dogs
}

\author{
Joshua M. Hare, * John F. Keaney, Jr., ${ }^{\star \ddagger}$ Jean-Luc Balligand, * Joseph Loscalzo, ${ }^{\star \star}$ Thomas W. Smith, * \\ and Wilson S. Colucci* \\ Departments of Medicine, *Brigham and Women's Hospital and Harvard Medical School, Boston, Massachusetts 02115; \\ and ${ }^{\ddagger}$ Brockton/West Roxbury Veterans Affairs Medical Center, Boston, Massachusetts 02132
}

\section{Abstract}

In vitro studies indicate that muscarinic cholinergic inhibition of $\beta$-adrenergic cardiac responses may be modulated in part by nitric oxide (NO). To evaluate the role of NO in parasympathetic inhibition of the $\beta$-adrenergic contractile response in vivo, we assessed the inotropic response to dobutamine before and during bilateral vagus nerve stimulation in closed-chest dogs. Dobutamine administration and vagal stimulation were repeated during intracoronary infusion of the NO synthase inhibitor $\boldsymbol{N}^{\mathbf{G}}$-monomethyl-L-arginine (L-NMMA, $10 \mu \mathrm{mol} / \mathrm{min}$ ) and again following infusion of L-arginine (100 $\mathrm{mg} / \mathrm{kg})$. In eight dogs, intracoronary dobutamine infusion at rates of 25 and $50 \mu \mathrm{g} / \mathrm{min}$ increased peak $+\mathrm{dP} / \mathrm{dt}$ by $131 \pm 24$ and $168 \pm 22 \%$, respectively $(P$ $<0.0001)$. Vagal stimulation $(2.5 \mathrm{~Hz})$ attenuated the responses to dobutamine ( 25 and $50 \mu \mathrm{g} / \mathrm{min}$ ) by $23 \pm 4$ and $21 \pm 4 \%$, respectively $(P<0.001)$. L-NMMA reduced (by $44-62 \% ; P<0.001$ ) and $L$-arginine restored vagal inhibition of the dobutamine-stimulated inotropic response. In a second group of nine dogs, dobutamine was administered systemically to assure a constant concentration in the coronary circulation. Vagal stimulation $(2.5 \mathrm{~Hz}$ ) attenuated the dobutamine-stimulated inotropic response $(2.5$ and $5.0 \mu \mathrm{g} /$ kg per min) by $40 \pm 12 \%$ and $57 \pm 8 \%$, respectively ( $P$ $<0.004)$. As with intracoronary dobutamine, L-NMMA diminished and $L$-arginine restored vagal inhibition of the inotropic response to dobutamine. Intracoronary infusion of atropine $(12 \mu \mathrm{g} / \mathrm{min})$ abolished the vagal inhibitory effect, and intracoronary infusion of 8-bromo-cyclic GMP (1 and $10 \mathrm{mM}$ ) caused a dose-dependent attenuation of the dobutamine-stimulated increase in $+\mathrm{dP} / \mathrm{dt}$. These data suggest that NO mediates, at least in part, vagal inhibition of the inotropic response to $\beta$-adrenergic stimulation by dobutamine, and thus may play a role in normal physiologic regulation of myocardial autonomic responses. (J. Clin. Invest. 1995. 95:360-366) Key words: automatic nervous system $\cdot$ vagus nerve $\cdot \mathrm{dP} / \mathrm{dt} \cdot$ nitric oxide $\cdot \beta$-adrenergic agonist

This work was presented in preliminary form at the 1994 American College of Cardiology Annual Scientific Session, Atlanta, GA, March 13-17, 1994.

Address correspondence to W. S. Colucci, Cardiovascular Division, Brigham and Women's Hospital, 75 Francis Street, Boston, MA 02115. Received for publication 14 December 1993 and in revised form 27 September 1994.

J. Clin. Invest.

(C) The American Society for Clinical Investigation, Inc.

0021-9738/95/01/0360/07 \$2.00

Volume 95, January 1995, 360-366

\section{Introduction}

The sympathetic and parasympathetic limbs of the autonomic nervous system play important and countervailing roles in regulating heart rate, atrioventricular conduction, and myocardial contractility. Sympathetic stimulation increases heart rate, conduction, and contractility, whereas parasympathetic stimulation slows both sinus node rate and atrioventricular conduction (16 ). Although it has little effect on ventricular contractility under basal conditions, an increase in vagal nerve activity attenuates the contractile response to sympathetic stimulation $(1,4)$ and infused $\beta$-adrenergic agonists $(2,3,5,6)$. Likewise, the intracoronary infusion of acetylcholine attenuates the inotropic response to sympathetic nerve stimulation (5) and infused $\beta$ adrenergic agonists $(5,6)$.

There is evidence to suggest that nitric oxide (NO $)^{1}$ may influence the autonomic regulation of cardiac function. In isolated myocytes, NO has been shown to play a role in both muscarinic-cholinergic slowing of heart rate and attenuation of the contractile response to $\beta$-adrenergic stimulation (7). NO acts by stimulating soluble guanylyl cyclase $(8-10)$ to produce cyclic GMP (cGMP). In the heart, muscarinic-cholinergic stimulation also leads to increased cGMP production (11-15) which, in turn, may counteract the contractile effects of cAMP $(16,17)$. Thus, there is theoretical support for the thesis that NO plays a role in modulating the interaction between the adrenergic and cholinergic arms of the autonomic nervous system.

Despite the well-characterized role of NO in modulating myocyte function in vitro, the role of NO in modulating myocardial contractility in vivo remains undefined. NO is involved in vagally mediated pulmonary (18) and coronary vasodilation (19), and in nonadrenergic, noncholinergic neurotransmission in animals $(20,21)$ and humans $(22,23)$. We report here the effect of NO synthase (NOS) inhibition on vagal modulation of the myocardial contractile response to $\beta$-adrenergic stimulation in normal dogs.

\section{Methods}

Animal preparation. Mongrel dogs $(n=18)$ weighing $26 \pm 0.6 \mathrm{~kg}$ were premedicated with $2.5 \mathrm{mg} / \mathrm{kg}$ intramuscular morphine sulfate (Roxane Laboratories, Inc., Columbus, $\mathrm{OH}$ ) and anesthetized with $80 \mathrm{mg} / \mathrm{kg} \alpha$ chloralose (Sigma Chemical Co., St. Louis, MO) dissolved in dimethyl sulfoxide (Sigma Chemical Co.). Animal protocols were approved by the Brockton/West Roxbury VA Medical Center Institutional Animal Care and Use Committee. Anesthesia was maintained with a constant infusion of $\alpha$-chloralose ( $16 \mathrm{mg} / \mathrm{kg}$ per h). Animals were intubated

1. Abbreviations used in this paper: cGMP, cyclic GMP; $+\mathrm{dP} / \mathrm{dt}$, rate of rise of left ventricular pressure; L-NMMA, $N^{\mathrm{G}}$-monomethyl-L-arginine; NO, nitric oxide; NOS, NO synthase; $\mathrm{V}_{\mathrm{PM}}$, maximal velocity of contractile element shortening. 
with a cuffed endotracheal tube and ventilated with $50 \%$ oxygen (12 breaths $/ \mathrm{min}, 20 \mathrm{ml} / \mathrm{kg}$ stroke vol) using a respirator (Drager AV; North American Drager, Telford, PA). Body temperature was monitored using a rectal probe and maintained with a homeothermic blanket (Harvard Apparatus Inc., Edinbridge, KY). Arterial blood gases were monitored (model ABC 30; Radiometer American Inc., Cleveland, $\mathrm{OH}$ ) and ventilator settings were adjusted or sodium bicarbonate was administered to maintain $\mathrm{pH}$ between 7.35 and 7.45, $\mathrm{PCO}_{2} 38-42$ Torr, and $\mathrm{Po}_{2} \geq 150$ Torr. The right femoral artery and vein were cannulated percutaneously with 7-French and 6-French sidearm sheaths (Cordis Laboratories, Inc., Miami, FL), respectively. The left femoral vein was cannulated with a 6-French sheath (Cordis Laboratories Inc.), and the left femoral artery was cannulated under direct visualization with a 10-French, 20-mm balloon valvuloplasty catheter (model J228-03; Mansfield Scientific, Mansfield, MA) that was advanced to the proximal portion of the descending aorta. Graded inflations and deflations of the balloon were used to regulate blood pressure during vagal nerve stimulation. The right external jugular vein was cannulated with a 7-French sidearm sheath (Cordis Laboratories Inc.), and the left carotid artery was cannulated with a 6-French sheath (Cordis Laboratories Inc.). Cutaneous leads were placed on all four extremities for continuous monitoring of the electrocardiogram. The bladder was catheterized with a 6-French urethral catheter (C.R. Bard Co., Inc., Covington, GA), and urine was drained into a graduated collection bag. After instrumentation, animals were heparinized with a 3,000-U bolus, followed by maintenance boluses of $1,000 \mathrm{U} / \mathrm{h}$.

Cervical vagus nerves were isolated bilaterally via a midline neck incision and ligated. Electrodes were applied distal to the ligatures bilaterally and connected to an electronic stimulator (model S48B; Grass Instrument Co., Quincy, MA). A 5-French high-fidelity micromanometer-tipped catheter (model SPC-350; Millar Instrument Inc., Houston, TX) was advanced to the left ventricle for measurement of left ventricular pressure. The rate of change of left ventricular pressure, $\mathrm{dP} / \mathrm{dt}$, was measured continuously by on-line differentiation of the pressure signal with an electronic differentiator (Gould Electronics Co., Columbus, $\mathrm{OH})$. Left ventricular pressure, left ventricular end-diastolic pressure, $\mathrm{dP} / \mathrm{dt}$, systemic BP, and a single-lead electrocardiogram were continuously recorded on a physiograph (model 2600; Gould Electronics Co.). Bipolar pacing catheters (5-French; C.R. Bard Co., Inc.) were positioned in the right atrial appendage and at the apex of the right ventricle.

\section{Experimental protocols}

Intracoronary dobutamine. Animals were allowed to stabilize for 30 min after instrumentation. After stabilization, intracoronary drug infusions were administered via a specifically designed 6-French catheter (Interventional Medical, Danvers, MA), positioned at the ostium of the left main coronary artery via the right femoral artery. Catheter placement was documented fluoroscopically before each intracoronary drug infusion. Dobutamine (Eli Lilly and Co., Indianapolis, IN) was infused into the coronary artery for $5 \mathrm{~min}$ at rates of 25 and $50 \mu \mathrm{g} / \mathrm{min}$. Hemodynamic responses were assessed at a constant paced heart rate. The right atrium was paced at a rate of 170 to 180 beats per min (bpm) $(\sim 10$ bpm above the rate achieved with the highest dose of dobutamine) using an external pacemaker (model 3070; Siemens Pacesetter, Sylmar, CA). Dual chamber pacing (atrioventricular interval $150 \mathrm{~ms}$ ) was used in two dogs in which vagal stimulation inhibited atrioventricular conduction. All hemodynamic measurements were performed at end-expiration and mean values were determined from the average of 10 consecutive cardiac cycles. After steady-state measurements, bilateral vagal nerve stimulation $(15 \mathrm{~V}, 0.5 \mathrm{~ms})$ was applied at 2.5 and $5.0 \mathrm{~Hz}$ in random order for $90 \mathrm{~s}$. Vagal nerve stimulation caused drops in mean BP of $\sim 15 \mathrm{mmHg}$. The intraaortic balloon was inflated in a graded fashion with an inflation device (model SM 2500; SciMed, Maple Grove, MN) to maintain BP within $10 \mathrm{mmHg}$ at a given dobutamine dose with and without vagal stimulation. Inhibition of NOS was achieved by intracoronary infusion of $N^{\mathrm{G}}$-monomethyl-L-arginine (L-NMMA; CalbiochemNovabiochem Corp., La Jolla, CA) at a rate of $10 \mu \mathrm{mol} / \mathrm{min}$ which yields a coronary concentration of $100 \mu \mathrm{M}$, assuming a total left coronary flow of $100 \mathrm{ml} / \mathrm{min}$ (19). After a 20-min infusion of L-NMMA and during concurrent administration of L-NMMA, vagal nerve stimulation was repeated without and with intracoronary infusion of dobutamine.

Intravenous dobutamine. Because L-NMMA attenuates both cholinergic (19) and $\beta$-adrenergic (24) vasodilator effects, the final coronary artery concentration of dobutamine infused via the coronary artery could potentially be higher during concurrent L-NMMA infusion. To assure delivery of a constant concentration of dobutamine to the myocardium, independent of coronary flow rates, in a second group of nine dogs, dobutamine was administered via a peripheral vein at rates of 2.5 and $5.0 \mu \mathrm{g} / \mathrm{kg}$ per min. As with the intracoronary protocol, these experiments were performed at a paced heart rate (dual chamber, atrioventricular sequential pacing) and with graded inflations of a balloon in the descending aorta to maintain arterial pressure constant to within 10 mmHg during vagal nerve stimulation. L-NMMA was administered by intracoronary infusion ( $10 \mu \mathrm{mol} / \mathrm{min}$ for $20 \mathrm{~min}$ ).

\section{Reversal of NOS inhibition with L-arginine}

To test the specificity of L-NMMA as an inhibitor of NOS, L-arginine ( $100 \mathrm{mg} / \mathrm{kg}$; Sigma Chemical Co.), the substrate for NOS (25), was administered as a peripheral bolus after L-NMMA infusion, and the effect of vagal nerve stimulation retested. The effect of L-arginine was tested in six of the dogs receiving intracoronary dobutamine and in all nine animals receiving intravenous dobutamine.

\section{The role of the muscarinic receptor}

To assess the dependence of vagal inhibition on the muscarinic receptor, five dogs underwent vagal stimulation $(2.5$ and $5.0 \mathrm{~Hz})$ before and during peripheral dobutamine infusion ( 2.5 and $5.0 \mu \mathrm{g} / \mathrm{kg}$ per min) while receiving an intracoronary infusion of atropine $(12 \mu \mathrm{g} / \mathrm{min})$, to yield a final intracoronary concentration of $0.4 \mu \mathrm{M}$ (assuming a left coronary flow of $100 \mathrm{cc} / \mathrm{min}$ ). To further elucidate the role of the NOcGMP pathway in vagal contractile inhibition, two-atropine-treated dogs received 8-bromo-cGMP ( 1 and $10 \mathrm{mM}$ at $1 \mathrm{~cm}^{3} / \mathrm{min}$ ), a nonhydrolyzable analogue of cGMP, by intracoronary infusion to yield final coronary artery concentrations of $\sim 10 \mu \mathrm{M}$ and $100 \mu \mathrm{M}$, respectively, during the peripheral administration of dobutamine $(5.0 \mu \mathrm{g} / \mathrm{kg}$ per $\mathrm{min})$.

\section{Hemodynamic measurements}

The peak rate of rise of left ventricular pressure $(+d P / d t)$ was used to assess contractility (26). The intracoronary infusion of drugs largely eliminates peripheral vascular effects (27) that might alter loading conditions and affect the utility of $+\mathrm{dP} / \mathrm{dt}$ as a contractile index. In addition, heart rate was held constant by pacing and an intraaortic balloon was inflated to maintain arterial pressure constant within $10 \mathrm{mmHg}$ during vagal stimulation.

Dobutamine caused a small increase in BP. Because of this, a second measure of contractility, the maximal velocity of contractile element shortening, $\mathrm{V}_{\mathrm{PM}}$, was also derived (26). This index, which is relatively afterload insensitive, is calculated as:

$\mathrm{V}_{\mathrm{PM}}=($ peak $+\mathrm{dP} / \mathrm{dt}) / \mathrm{P}_{\mathrm{dev}}$

where $P_{\text {dev }}=$ left ventricular peak systolic pressure - left ventricular end-diastolic pressure. Coronary perfusion was calculated as aortic diastolic pressure - left ventricular end-diastolic pressure.

\section{Data analysis}

Data are presented as mean \pm SEM. Concentration-effect relationships for dobutamine in the presence and absence of L-NMMA or vagal nerve stimulation were compared using ANOVA with repeated measures (28). The effects of L-NMMA and L-arginine on the responses to vagal stimulation were assessed with three-way ANOVA using as terms $(a)$ the dobutamine dose, $(b)$ the presence or absence of L-NMMA, and $(c)$ an identification term to match individual dog data. To determine whether the L-NMMA or L-arginine treatment effects depended on dobutamine dose, a factorial design ANOVA analysis was performed to test the statistical significance of an interaction term (treatment dose $\times$ dobutamine) (28). A significant interaction term indicates that the treatment effect depends on the dobutamine dose, and post hoc testing is required 
Table I. The Contractile Response to Intracoronary Dobutamine: Effect of L-NMMA

\begin{tabular}{|c|c|c|c|c|c|c|}
\hline & \multicolumn{2}{|c|}{ Dobutamine $(0 \mu \mathrm{g} / \mathrm{min})$} & \multicolumn{2}{|c|}{ Dobutamine $(25 \mu \mathrm{g} / \mathrm{min})$} & \multicolumn{2}{|c|}{ Dobutamine $(50 \mu \mathrm{g} / \mathrm{min})$} \\
\hline & -L-NMMA & +L-NMMA & -L-NMMA & +L-NMMA & -L-NMMA & +L-NMMA \\
\hline$+\mathrm{dP} / \mathrm{dt}_{\max }(\mathrm{mmHg} / \mathrm{s})$ & $2,445 \pm 181$ & $2,055 \pm 242$ & $5,672 \pm 803^{*}$ & $5,109 \pm 521^{\ddagger}$ & $6,477 \pm 706^{*}$ & $6,547 \pm 866^{\ddagger}$ \\
\hline$V_{P M}\left(s^{-1}\right)$ & $15.8 \pm 0.9$ & $15.1 \pm 0.9$ & $29.9 \pm 2.1^{8}$ & $26.3 \pm 1.4^{8}$ & $31.9 \pm 1.6^{8}$ & $31.3 \pm 2.1^{8}$ \\
\hline
\end{tabular}

Animals were prepared as described in Methods. Heart rate was maintained constant by pacing at $10 \mathrm{bpm}$ above the maximum heart rate achieved with dobutamine. Results represent mean \pm SEM from eight animals. $\mathrm{V}_{\mathrm{PM}}=\left(+\mathrm{dP} / \mathrm{dt}_{\max }\right) / \mathrm{P}_{\mathrm{dev}}{ }^{*} P<0.0005 ;{ }^{\ddagger} P<0.0002$; and ${ }^{\S} P<0.0001$ for dobutamine effect (ANOVA with repeated measures).

(28). Conversely, an insignificant interaction term is evidence that the treatment effect was unaltered by the dobutamine dose. Statistical analyses were performed both for absolute measurements, and in some cases, for percentage change from baseline. The effects of vagal stimulation during atropine infusions were similarly analyzed by three-way ANOVA. Post hoc, univariate $t$ tests with the Bonferonni correction were used to assess the statistical significance of changes in $+\mathrm{dP} / \mathrm{dt}$ induced by vagal stimulation. Changes were considered significant if the null hypothesis was rejected at a level of $P<0.05$.

\section{Results}

Effect of vagal nerve stimulation on the positive inotropic response to intracoronary dobutamine. Before infusion of intracoronary dobutamine, baseline $+\mathrm{dP} / \mathrm{dt}$ was $2,445 \pm 181 \mathrm{mmHg}$ / $\mathrm{s}$ (Table I). Vagal nerve stimulation at 2.5 and $5.0 \mathrm{~Hz}$ reduced the baseline $+\mathrm{dP} / \mathrm{dt}$ by $223 \pm 85 \mathrm{mmHg} / \mathrm{s}(P=\mathrm{NS})$ and $297 \pm 120 \mathrm{mmHg}(P=\mathrm{NS})$, respectively.

With the intracoronary infusion of dobutamine at rates of 25 and $50 \mu \mathrm{g} / \mathrm{min},+\mathrm{dP} / \mathrm{dt}$ increased by $3,227 \pm 714 \mathrm{mmHg} / \mathrm{s}$ and $4,031 \pm 627 \mathrm{mmHg} / \mathrm{s}$, respectively $(P<0.0005$ by $\mathrm{AN}-$ OVA with repeated measures; Table I and Fig. 1). During dobutamine infusion at 25 and $50 \mu \mathrm{g} / \mathrm{min}$, vagal nerve stimulation at $2.5 \mathrm{~Hz}$ attenuated $+\mathrm{dP} / \mathrm{dt}$ by $781 \pm 216 \mathrm{mmHg}$ and $789 \pm 164 \mathrm{mmHg}$, respectively $(P<0.001$ by ANOVA with repeated measures, Fig. 1). Vagal stimulation at $5.0 \mathrm{~Hz}$ had an inhibitory effect similar to stimulation at $2.5 \mathrm{~Hz}$ (Fig. 1). These findings are qualitatively and quantitatively similar to prior observations by Henning et al. (4), and demonstrate that, although having relatively little effect in the absence of sympathetic tone, vagal nerve stimulation attenuates the positive inotropic response to dobutamine.

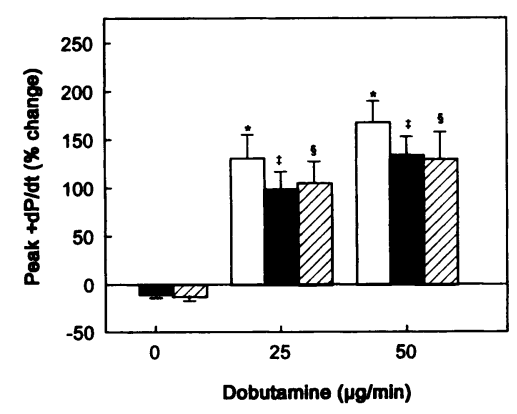

Figure 1. The effect of vagal nerve stimulation on the inotropic response to intracoronary dobutamine. Dobutamine was infused into the left main-coronary ostium at the indicated rates for 5 min. Vagal nerves were stimulated bilaterally for 90 s. Peak $+d P / d t$ was recorded before vagal stimulation (open bars) and after vagal nerve stimulation at $2.5 \mathrm{~Hz}$ (solid bars) or $5 \mathrm{~Hz}$ (hatched bars). Data are presented as percent change from baseline and represent the mean \pm SEM for eight dogs. ${ }^{*} P$ $<0.0001$ vs baseline; ${ }^{\ddagger} P<0.001$ vs dobutamine alone; ${ }^{8} P<0.01$ vs dobutamine alone, as indicated (ANOVA with repeated measures).
Effect of NOS inhibition on the response to vagal nerve stimulation. After intracoronary infusion of L-NMMA (10 $\mu \mathrm{mol} / \mathrm{min}$ for $20 \mathrm{~min}$ ), $+\mathrm{dP} / \mathrm{dt}$ was $2,055 \pm 242 \mathrm{mmHg} / \mathrm{s}$ ( Table I, $P=$ NS vs before L-NMMA). L-NMMA did not affect the dobutamine-stimulated increase in $+\mathrm{dP} / \mathrm{dt}$ or $\mathrm{V}_{\mathrm{PM}}$ (Table I), but significantly reduced the ability of vagal nerve stimulation $(2.5 \mathrm{~Hz})$ to inhibit the contractile response to dobutamine by $62 \pm 8$ and $44 \pm 15 \%$ at dobutamine infusion rates of 25 and $50 \mu \mathrm{g} / \mathrm{min}$, respectively $(P<0.001$ by three-way ANOVA; Fig. 2). Factorial analysis revealed an insignificant interaction term $(F=0.06, P=0.95)$ indicating a similar effect of $L$ NMMA at all infusion rates of dobutamine. L-NMMA attenuated, to a similar degree, the vagal inhibitory effect at $5.0 \mathrm{~Hz}$ (data not shown).

Role of loading conditions and heart rate. The intracoronary infusion of L-NMMA had no effect on mean arterial pressure, left ventricular end-diastolic pressure, or coronary perfusion pressure (Table II). Both mean arterial pressure $(P<0.0002$ by ANOVA) and coronary perfusion pressure $(P<0.0001$ by ANOVA) increased with infusion of dobutamine; however, neither was affected by L-NMMA administration. Decreases in blood pressure with vagal nerve stimulation were circumvented by graded inflation of an intraaortic balloon to maintain blood pressure within $10 \mathrm{mmHg}$ of the baseline value.

To exclude further potential confounding effects of changes in arterial pressure on $+\mathrm{dP} / \mathrm{dt}$, a second, relatively load-insensitive index of contractility, $\mathrm{V}_{\mathrm{PM}}(26)$, was also calculated (Table I). Vagal nerve stimulation $(2.5 \mathrm{~Hz})$ inhibited the $\mathrm{V}_{\mathrm{PM}}$ response to dobutamine by $3.3 \pm 1.1 \mathrm{~s}^{-1}(-18 \pm 9 \%)$ and $2.3 \pm 0.3 \mathrm{~s}^{-1}$ $(-15 \pm 2 \%)$, at dobutamine infusion rates of 25 and $50 \mu \mathrm{g} / \mathrm{min}$, respectively ( $P=0.01$, ANOVA with repeated measures). L-NMMA attenuated the ability of vagal stimulation to antago-

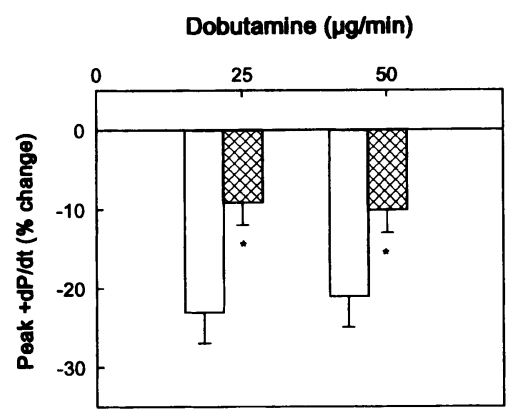

Figure 2. The effect of L-NMMA in modulating the vagal inhibitory effect over the contractile response to intracoronary dobutamine. Intracoronary dobutamine infusion and vagal nerve stimulation $(2.5 \mathrm{~Hz}$ for $90 \mathrm{~s})$ were as per Fig. 1. The inhibitory effect of vagal nerve stimulation without L-NMMA (open

bars) was significantly attenuated by the intracoronary infusion of LNMMA (cross-hatched bars). Data depicted are the mean \pm SEM for eight dogs. ${ }^{*} P<0.001$ vs without L-NMMA (by three-way ANOVA). 
Table II. Loading Conditions: Intracoronary Dobutamine Protocol

\begin{tabular}{|c|c|c|c|c|c|c|}
\hline & \multicolumn{2}{|c|}{ Dobutamine $(0 \mu \mathrm{g} / \mathrm{min})$} & \multicolumn{2}{|c|}{ Dobutamine $(25 \mu \mathrm{g} / \mathrm{min})$} & \multicolumn{2}{|c|}{ Dobutamine $(50 \mu \mathrm{g} / \mathrm{min})$} \\
\hline & -L-NMMA & +L-NMMA & -L-NMMA & +L-NMMA & -L-NMMA & +L-NMMA \\
\hline HR (bpm) & $181 \pm 5$ & $186 \pm 7$ & $192 \pm 5$ & $194 \pm 4$ & $195 \pm 4$ & $194 \pm 5$ \\
\hline MAP (mmHg) & $154 \pm 8$ & $132 \pm 6$ & $168 \pm 10^{*}$ & $179 \pm 12 *$ & $178 \pm 12 *$ & $175 \pm 12 *$ \\
\hline LVEDP (mmHg) & $7 \pm 3$ & $9 \pm 3$ & $2 \pm 1$ & $3 \pm 1$ & $2 \pm 1$ & $3 \pm 1$ \\
\hline $\mathrm{CPP}(\mathrm{mmHg})$ & $135 \pm 7$ & $113 \pm 8$ & $153 \pm 8^{\ddagger}$ & $161 \pm 10^{\ddagger}$ & $162 \pm 10^{\ddagger}$ & $160 \pm 9^{\ddagger}$ \\
\hline
\end{tabular}

Animals were prepared as described in Methods. Heart rate was maintained constant by pacing at $10 \mathrm{bpm}$ above the maximum heart rate achieved with dobutamine. Results represent mean \pm SEM from nine animals. HR, heart rate; MAP, mean arterial pressure; LVEDP, left ventricular enddiastolic pressure; CPP, coronary perfusion pressure. ${ }^{*} P<0.0002$ and ${ }^{\ddagger} P<0.0001$ for dobutamine effect (three-way ANOVA).

nize the dobutamine-stimulated $\mathrm{V}_{\mathrm{PM}}$ response by $34 \pm 23 \%$ and $62 \pm 10 \%(P<0.04$ for L-NMMA effect by three-way ANOVA) at dobutamine infusion rates of 25 and $50 \mu \mathrm{g} / \mathrm{min}$, respectively. An insignificant interaction term $(\mathrm{F}=0.22, P$ $=0.8$ ) indicated that this effect was similar at both dobutamine infusion rates. Thus, the effect of L-NMMA, as assessed by $\mathrm{V}_{\mathrm{PM}}$, was qualitatively and quantitatively similar to that seen with $+\mathrm{dP} / \mathrm{dt}$.

Peripheral dobutamine infusion. Since NOS inhibition may inhibit the coronary vasodilator effects of vagal and/or $\beta$-adrenergic stimulation, coronary blood flow could potentially be reduced during L-NMMA infusions. If this were the case, the relative dobutamine concentrations achieved with intracoronary infusions would be increased by L-NMMA. To address this possibility, in nine dogs dobutamine was administered intravenously to assure a constant concentration in the coronary circulation, independent of any change in coronary blood flow.

Before the administration of peripheral dobutamine, baseline $+\mathrm{dP} / \mathrm{dt}$ was $2,667 \pm 199 \mathrm{mmHg} / \mathrm{s}$. The response to vagal nerve stimulation in the presence and absence of peripheral dobutamine is depicted in Fig. 3. In the absence of dobutamine, vagal nerve stimulation decreased $+\mathrm{dP} / \mathrm{dt}$ by $181 \pm 79(P=\mathrm{ns})$ and $195 \pm 134 \mathrm{mmHg}(P=\mathrm{ns})$ at 2.5 and $5.0 \mathrm{~Hz}$, respectively. Peripheral dobutamine infusion at rates of 2.5 and $5.0 \mu \mathrm{g} / \mathrm{kg}$ per min increased $+\mathrm{dP} / \mathrm{dt}$ by $2,319 \pm 348$ and $3,250 \pm 495 \mathrm{mmHg}$, respectively ( $P<0.0001$ by ANOVA with repeated measures). Vagal nerve stimulation at $2.5 \mathrm{~Hz}$ inhibited the contractile responses to dobutamine by $40 \pm 12$ and $57 \pm 8 \%$ ( $P<0.004$ by ANOVA with repeated measures) at infusion rates of 2.5 and

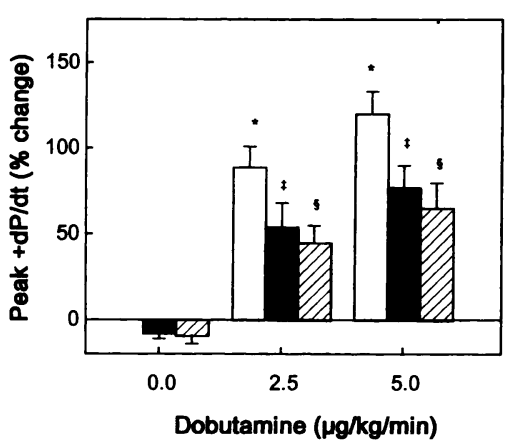

Figure 3. The effect of vagal nerve stimulation on the inotropic response to peripheral dobutamine. Dobutamine was infused by peripheral vein at the indicated rates for $5 \mathrm{~min}$. Vagal nerves were stimulated bilaterally for $90 \mathrm{~s}$. Peak $+\mathrm{dP} /$ dt was recorded before vagal stimulation (open bars) and after vagal

stimulation at $2.5 \mu \mathrm{g} / \mathrm{kg}$ per min (solid bars) and $5.0 \mu \mathrm{g} / \mathrm{kg}$ per min (hatched bars). Data are presented as percent size from baseline and represent the mean \pm SEM for nine dogs. $* P=0.0001{ }^{\ddagger}{ }^{\ddagger} P<0.004 ;{ }^{\&}$ $P=0.0001$ vs dobutamine alone, as indicated (ANOVA with repeated measures).
$5.0 \mu \mathrm{g} / \mathrm{kg}$ per min, respectively. The vagal inhibitory response at $5.0 \mathrm{~Hz}$ was of a similar magnitude.

As with intracoronary dobutamine infusion, L-NMMA did not affect the contractile response to peripheral dobutamine (data not shown), but significantly attenuated vagal inhibition of the dobutamine-stimulated increase in peak $+\mathrm{dP} / \mathrm{dt}$ (Table III and Fig. 4). The effect of L-NMMA was not dependent on the infusion rate of dobutamine. As with the intracoronary infusion protocol, mean arterial pressure and coronary perfusion pressure were not affected by intracoronary L-NMMA (Table IV).

Reversal of L-NMMA with L-arginine. To confirm that the effect of L-NMMA was specific for inhibition of NOS, L-arginine was infused via a peripheral vein (bolus, $100 \mathrm{mg} / \mathrm{kg}$ ) immediately after the infusion of L-NMMA. As depicted in Table III and Fig. 4, L-arginine restored the inhibitory effect of vagal nerve stimulation toward control values $(P<0.01$ vs L-NMMA and $P=$ NS vs baseline). L-arginine had a similar effect during intracoronary dobutamine infusion $(n=6$, data not shown).

Effects of muscarinic receptor blockade and exogenous $c G M P$. Vagal-stimulated NO activity in the heart could occur in

Table III. Absolute Reduction in Peak $+d P / d t(m m H g / s)$ by Vagal Nerve Stimulation during Peripheral Dobutamine

\begin{tabular}{cccc}
\hline & Baseline & L-NMMA & L-Arginine \\
\hline Dobutamine & & & \\
$0 \mu \mathrm{g} / \mathrm{kg}$ per min & & & \\
$\quad$ Vag stim $2.5 \mathrm{~Hz}$ & $-181 \pm 79$ & $-143 \pm 64^{*}$ & $-179 \pm 97^{\ddagger}$ \\
Vag stim $5.0 \mathrm{~Hz}$ & $-195 \pm 134$ & $-107 \pm 64^{*}$ & $-333 \pm 163^{\S}$ \\
$2.5 \mu \mathrm{g} / \mathrm{kg}$ per min & & & \\
Vag stim $2.5 \mathrm{~Hz}$ & $-889 \pm 261$ & $-348 \pm 146^{*}$ & $-875 \pm 241^{\ddagger}$ \\
Vag stim $5.0 \mathrm{~Hz}$ & $-1,111 \pm 99$ & $-688 \pm 188^{*}$ & $-1,333 \pm 228^{\S}$ \\
$5.0 \mu \mathrm{g} / \mathrm{kg}$ per min & & & \\
Vag stim $2.5 \mathrm{~Hz}$ & $-1,153 \pm 287$ & $-357 \pm 148^{*}$ & $-958 \pm 168^{\ddagger}$ \\
Vag stim $5.0 \mathrm{~Hz}$ & $-1,486 \pm 185$ & $-714 \pm 247^{*}$ & $-1,133 \pm 179^{\S}$
\end{tabular}

Data represent absolute reduction in peak $+\mathrm{dP} / \mathrm{dt}$ by vagal nerve stimulation (Vag stim) at the indicated freuqencies during concurrent intravenous administration of dobutamine at the indicated rates. Measurements were obtained at baseline, during intracoronary administration of L-NMMA $(10 \mu \mathrm{mol} / \mathrm{min})$ and after reversal of NOS inhibition by an intravenous bolus of $\mathrm{L}$-arginine $(100 \mathrm{mg} / \mathrm{kg}) .{ }^{*} P<0.03$ for L-NMMA effect vs baseline at corresponding vagal stimulation frequency (threeway ANOVA). ${ }^{\ddagger} P<0.01$ and ${ }^{8} P<0.03$ for L-arginine vs L-NMMA at corresponding vagal stimulation frequency (three-way ANOVA). 


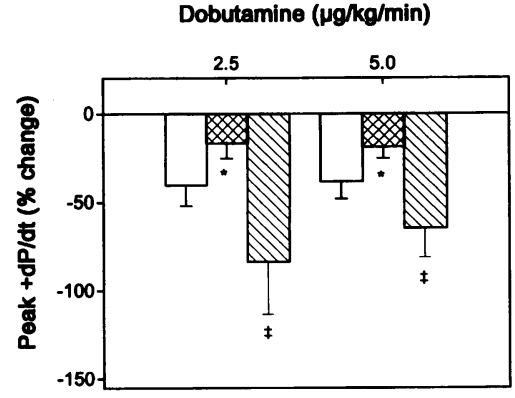

Figure 4. The effects of L-NMMA and L-arginine on vagal attenuation of the contractile response to a systemic infusion of dobutamine. In the absence of L-NMMA ( open bars), vagal stimulation at $2.5 \mathrm{~Hz}$ decreased $+\mathrm{dP}$ dt at dobutamine infusion rates of 2.5 and 5.0 $\mu \mathrm{g} / \mathrm{kg}$ per min. In the presence of intracoronary

L-NMMA (cross-hatched bars), the effect of vagal stimulation to decrease $+\mathrm{d} P / \mathrm{dt}$ was significantly inhibited, as indicated. Systemic Larginine (hatched bars) significantly reversed the effect of L-NMMA. The data depicted are the mean \pm SEM for nine dogs. $* P<0.04$ vs baseline; ${ }^{\ddagger} P<0.02$ vs L-NMMA, as indicated (by three-way ANOVA).

parallel (i.e., neuronal release) or in series with the muscarinic receptor. To distinguish between these possibilities, vagal stimulation before and during peripheral dobutamine infusion ( 2.5 and $5.0 \mu \mathrm{g} / \mathrm{kg}$ per min) was performed in dogs $(n=5)$ during the intracoronary infusion of atropine $(12 \mu \mathrm{g} / \mathrm{min})$. Atropine abolished vagal inhibition of the dobutamine-stimulated increase in $+\mathrm{dP} / \mathrm{dt}$ (Fig. 5 ).

To assess whether cGMP could simulate the inhibitory effect of vagal nerve stimulation, 8-bromo-cGMP was infused after intracoronary atropine via the left coronary artery in two dogs during peripheral infusion of dobutamine $(5 \mu \mathrm{g} / \mathrm{kg}$ per min). With dobutamine alone, $+\mathrm{dP} / \mathrm{dt}$ increased by $49 \pm 4 \%$ (from $2,563 \pm 44 \mathrm{mmHg}$ to $3,813 \pm 44 \mathrm{mmHg}$ ). 8-bromo-cGMP, at coronary artery concentrations of $\sim 10$ and $100 \mu \mathrm{M}$, attenuated the dobutamine-stimulated increases in $+\mathrm{dP} / \mathrm{dt}$ by $45 \pm 1 \%$ and $74 \pm 5 \%$, respectively. Vagal stimulation at $5.0 \mathrm{~Hz}$ attenuated the dobutamine response by $74 \pm 24 \%$ in these animals.

\section{Discussion}

This study tested the hypothesis that NO is involved in the autonomic regulation of myocardial contractility in normal dogs. Using both intracoronary and intravenous dobutamine as a $\beta$-adrenergic stimulus, and the direct stimulation of the cervical vagus nerves to increase cardiac parasympathetic tone, we reproduced the well-described antagonistic interaction between the parasympathetic and sympathetic limbs of the autonomic nervous system $(1-6)$. The role of NO was tested by inhibiting
NOS with the concurrent intracoronary infusion of L-NMMA. Under the conditions of this study, L-NMMA significantly reduced by the inhibitory effect of vagal nerve stimulation by $\sim 60 \%$. We further demonstrated that the vagal inhibitory effect can be restored by L-arginine, eliminated by atropine, and mimicked by 8-bromo-cGMP.

Several lines of evidence now support a role for NO in the physiologic regulation of the heart. Shulz et al. (29) demonstrated NOS activity in rat ventricular tissue by measuring the formation of L-citrulline, which is produced in the conversion of L-arginine to NO (25). In cultured myocytes, Balligand et al. (7) have demonstrated that cholinergic agonists stimulated NO production and that inhibition of NOS attenuated the slowing of myocyte beating rate by cholinergic agonists. These findings suggest that NO modulates parasympathetic effects on heart rate $(7)$.

There is controversy as to whether NO influences basal myocardial contractility. Balligand et al. (7) found that NOS inhibition did not affect basal contractility, but augmented the contractile response to $\beta$-adrenergic stimulation. In contrast, Brady et al. demonstrated that NO, as delivered by nitroprusside or as NO gas in solution, exerted a negative inotropic effect in cultured guinea pig myocytes (30). Data from other studies in isolated myocytes (7) and humans (31) have not confirmed these observations. In the present study, we did not observe an effect of L-NMMA on basal $+\mathrm{dP} / \mathrm{dt}$. Thus, the influence of NO on contractility may be more apparent in the presence of $\beta$ adrenergic stimulation.

We explored the mechanism by which L-NMMA attenuated vagal inhibition of the contractile response to dobutamine. Larginine, the substrate for NOS (25), restored the ability of vagal stimulation to attenuate the dobutamine response. This finding supports the conclusion that the observed effect of $\mathrm{L}$ NMMA is mediated via inhibition of NOS. Certain arginine analogues, notably the alkyl esters, act as muscarinic receptor inhibitors (32). However, L-NMMA, the NOS inhibitor used in this study has been demonstrated not to inhibit the muscarinic receptor (32). It should be noted that the intracoronary LNMMA concentration of $\sim 100 \mu \mathrm{M}$ achieved in this study may not inhibit NOS fully $(33,34)$, and thus may underestimate the role of NO.

Secondly, to assess whether the vagal inhibitory effect depended on an intact muscarinic receptor, the contractile effects of vagal nerve stimulation on dobutamine were assessed in atropine-treated dogs. The complete elimination of the vagal inhibitory effect by atropine indicates that vagal-stimulated NO activity occurs in series with stimulation of the muscarinic re-

Table IV. Loading Conditions: Peripheral Dobutamine

\begin{tabular}{|c|c|c|c|c|c|c|}
\hline & \multicolumn{2}{|c|}{ Dobutamine $(0 \mu \mathrm{g} / \mathrm{kg}$ per min) } & \multicolumn{2}{|c|}{ Dobutamine $(2.5 \mu \mathrm{g} / \mathrm{kg}$ per $\mathrm{min})$} & \multicolumn{2}{|c|}{ Dobutamine $(5.0 \mu \mathrm{g} / \mathrm{kg}$ per min) } \\
\hline & -L-NMMA & +L-NMMA & -L-NMMA & +L-NMMA & -L-NMMA & +L-NMMA \\
\hline HR (bpm) & $173 \pm 3$ & $177 \pm 1$ & $174 \pm 2$ & $178 \pm 1$ & $184 \pm 6$ & $184 \pm 5$ \\
\hline MAP (mmHg) & $138 \pm 8$ & $125 \pm 6$ & $175 \pm 15^{*}$ & $157 \pm 15^{*}$ & $167 \pm 8^{*}$ & $159 \pm 13^{*}$ \\
\hline LVEDP (mmHg) & $8 \pm 2$ & $10 \pm 4$ & $5 \pm 1$ & $8 \pm 3$ & $4 \pm 1$ & $5 \pm 1$ \\
\hline CPP (mmHg) & $116 \pm 4$ & $106 \pm 5$ & $157 \pm 9 *$ & $137 \pm 11^{*}$ & $149 \pm 8^{*}$ & $142 \pm 11^{*}$ \\
\hline
\end{tabular}

Animals were prepared as described in Methods. Heart rate was maintained constant by pacing at $10 \mathrm{bpm}$ above the maximum heart rate achieved with dobutamine. Results represent mean \pm SEM from nine animals. HR, heart rate; MAP, mean arterial pressure; LVEDP, left ventricular enddiastolic pressure; CPP, coronary perfusion. ${ }^{*} P<0.0001$ for dobutamine effect (three-way ANOVA). 


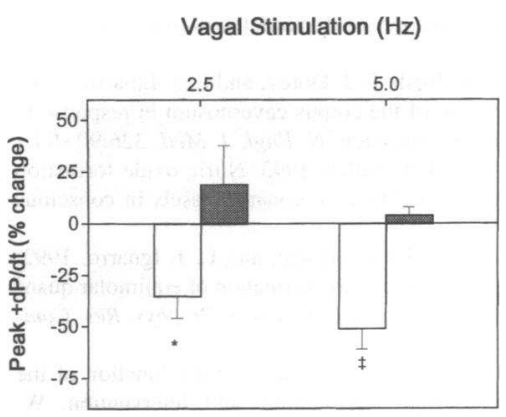

Figure 5. The effect of atropine on the vagal inhibition of the contractile response to a systemic infusion of dobutamine. Dobutamine was infused by peripheral vein at 5 $\mu \mathrm{g} / \mathrm{kg}$ per min for $5 \mathrm{~min}$ during the concurrent intracoronary infusion of atropine $12 \mu \mathrm{g} / \mathrm{min}$. Vagal nerves were stimu-

lated bilaterally for $90 \mathrm{~s}$ at the indicated rates. Vagal stimulation at baseline (open bars) produced significant inhibition of the inotropic response to dobutamine. In the presence of intracoronary atropine (grey bars), the vagal inhibitory effect is abolished. The data depicted are the mean \pm SEM for five dogs. ${ }^{*} P<0.01 ;{ }^{\ddagger} P<0.005$.

ceptor. 8-bromo-cGMP mimicked the attenuation of the dobutamine contractile response, indicating that cGMP can bypass the muscarinic blockade.

Certain methodologic issues should be considered. First, in vivo administration of an NOS inhibitor might affect coronary blood flow. There is evidence that NO contributes to both cholinergic (19) and adrenergic (24) coronary vasodilation, and if L-NMMA inhibits coronary vasodilation during vagal stimulation and/or the infusion of dobutamine, the final concentration of an agent infused via the coronary artery might be increased. To exclude this explanation for our observations, dobutamine was also infused by a systemic vein, thereby assuring the delivery of a constant concentration of drug to the myocardium, independent of coronary blood flow. With this protocol, as with the intracoronary infusion of dobutamine, L-NMMA attenuated the vagal inhibition of the contractile response to dobutamine. Thus, the effect of L-NMMA observed in these studies cannot be attributed to changes in coronary blood flow.

Second, loading conditions can affect $+\mathrm{dP} / \mathrm{dt}$. Although loading conditions were not affected by L-NMMA, dobutamine produced a small increase in systemic blood pressure. To control for this effect, $V_{P M}$, the maximal velocity of contractile element shortening, a relatively load-independent index of contractility, was also examined (26). Using this index, the effect of vagal stimulation and the attenuation of this effect by NOS inhibition were qualitatively and quantitatively similar to the effects observed with peak $+\mathrm{dP} / \mathrm{dt}$. Therefore, it is unlikely that our observations are dependent on the minor changes in blood pressure that occurred.

Previous studies have provided evidence that muscarinic receptor stimulation stimulates NO activity. Cholinergic stimulation has been shown to increases myocardial cGMP (11). Furthermore, nonhydrolyzable analogues of cGMP, such as dibutyryl cGMP or 8-bromo-cGMP, inhibit both the rate (35) and amplitude $(36,37)$ of myocyte contraction in vitro, thus mimicking the effects of cholinergic agonists. Of note, the negative inotropic effect of acetylcholine correlates with the increase in myocardial cGMP (12) in the isolated perfused rat heart. Thus, it is reasonable to suggest that vagal stimulation exerts a negative inotropic effect, at least in part, via an NO-mediated increase in cGMP.

Traditionally, muscarinic effects on contractility have been ascribed to activation of an inhibitory $G$ protein that reduces the production of cAMP by adenylyl cyclase (15). Reductions in cAMP levels in response to muscarinic stimulation, however, have not been consistently demonstrated (14). Our data suggest that a second, NO-dependent, and presumably cGMP-mediated, mechanism may also be involved. There are several possible mechanisms by which cGMP might attenuate myocyte contractility. cGMP may inhibit the L-type slow inward $\mathrm{Ca}^{2+}$ current in myocardium by either the stimulation of a cGMP-dependent cAMP phosphodiesterase (16) and/or via a cGMP protein kinase (17). More recently, NO donors have been shown to inhibit $\beta$-adrenergic-stimulated rises in inward $\mathrm{Ca}^{2+}$ current in frog myocytes (38) and rabbit sinoatrial cells (39). Han and colleagues (39) have further shown that cholinergic inhibition of $\beta$-adrenergic-stimulated inward $\mathrm{Ca}^{2+}$ current can be blocked by L-NMMA. In addition to influencing contractility through the slow inward $\mathrm{Ca}^{2+}$ current, a recent report indicates that activation of cGMP protein kinase (36) may decrease myofilament responsiveness to calcium in rat myocytes. Neither LNMMA nor L-arginine have been reported to directly affect the $\mathrm{G}_{\mathrm{i}}$ pathway.

While this and other studies strongly suggest that NO has a physiologic function in the heart, its cell ( $s$ ) of origin has not been determined. Several potential sources of NO exist in the heart. Cardiac myocytes, per se, appear capable of NO synthesis $(7,40)$. Endothelial cells represent another possible source of cardiac NO (19), including constitutive production by largevessel endothelium and inducible production by cardiac microvascular endothelium (41). Neurons represent a third possible source of cardiac NO. In this regard, Klimaschewski et al. have shown evidence of NOS containing ganglion cells and nerve fibers that innervate sinoatrial, atrioventricular, ventricular myocardial, and smooth muscle cells in rats and guinea pigs (42).

In addition to its role in normal physiologic regulation of myocardial contractility, the negative inotropic effects of NO may be relevant to pathophysiologic states associated with myocardial depression. NO has been implicated as a cause of left ventricular dysfunction associated with sepsis and other states of elevated cytokines. In isolated myocytes, Balligand et al. showed that inflammatory cytokines induced depression in the contractile response to a $\beta$-adrenergic agonist that was restored to normal by treatment with L-NMMA (43). Similarly, Brady et al., using isolated adult guinea pig myocytes, showed that NOS inhibition restored the reduced contractile amplitude of myocytes from endotoxin-treated animals (44). Cytokines may increase myocardial NO production by the stimulation of an inducible isoform of NOS $(29,40,41)$.

In summary, these observations show, for the first time in vivo, that NO is involved in the parasympathetic regulation of myocardial contractility. We have previously shown that muscarinic-cholinergic stimulation of the human heart, via the intracoronary infusion of acetylcholine, inhibits the positive inotropic response to $\beta$-adrenergic stimulation (6). The present findings, therefore, have implications for normal human physiology and may be relevant to pathophysiologic states associated with increased NO production.

\section{Acknowledgments}

The authors are grateful to Drs. Thomas Michel and Ralph A. Kelly for generous scientific input, and wish to acknowledge the technical assistance of Steve Conroy, James Carr, and Ronald Brown.

This work was supported in part by grants HL-425309 (W. S. Colucci) and HL-36141 (T. W. Smith) from the National Institutes of Health (NIH). J. F. Keaney is the recipient of an NIH National Research Service Award (F32 HL-08635). J.-L. Balligand is supported by a 
fellowship from the American Heart Association, Massachusetts affiliate. J. Loscalzo is the recipient of an NIH Research Career Development Award (K04 HL-02273), NIH grants HL-48743, HL-53919, a VA merit review award and a grant from NitroMed, Inc. W. S. Colucci was a Sandoz Established Investigator of the American Heart Association.

\section{References}

1. Levy, M. N., M. Ng, P. Martin, and H. Zieske. 1966. Sympathetic and parasympathetic interactions upon the left ventricle of the dog. Circ. Res. 19:510.

2. Vatner, S. F., J. S. Rutherford, and H. R. Ochs. 1979. Baroreflex and vagal mechanisms modulating left ventricular contractile responses to sympathetic amines in conscious dogs. Circ. Res. 44:195-207.

3. Fujii, A. M., and S. F. Vatner. 1985. Autonomic mechanisms regulating myocardial contractility in conscious animal. Pharmacol. \& Ther. 29:221-238.

4. Henning, R. J., I. R. Khalil, and M. N. Levy. 1990. Vagal stimulation attenuates sympathetic enhancement of left ventricular function. Am. J. Physiol. 258:H1470-H1475.

5. Ross, G. 1973. Effects of intracoronary infusions of acetylcholine and nicotine on the dog heart in vivo. Br. J. Pharmacol. 48:612-619.

6. Landzberg, J. S., J. D. Parker, D. F. Gauthier, and W. S. Colucci. 1994. Effects of intracoronary acetylcholine and atropine on basal and dobutaminestimulated left ventricular contractility. Circulation. 89:164-168.

7. Balligand, J.-L., R. A. Kelly, P. A. Marsden, T. W. Smith, and T. Michel, 1993. Control of cardiac muscle cell function by an endogenous nitric oxide signalling system. Proc. Natl. Acad. Sci. USA. 90:347-351.

8. Ignarro, L. J., T. M. Burke, K. S. Wood, M. S. Wolin, and P. J. Kadowitz. 1984. Association between cyclic GMP accumulation and acetylcholine-elicited relaxation of bovine intrapulmonary artery. J. Pharmacol. Exp. Ther. 228:682690.

9. Radomski, M. W., R. J. J. Palmer, and S. Moncada. 1987. The role of nitric oxide and cGMP in platelet adhesion to the vascular endothelium. Biochem. Biophys. Res. Commun. 148:1482-1489.

10. Kubes, P., and D. N. Granger. 1992. Nitric oxide modulates microvascular permeability. Am. J. Physiol. 262:H611-H615.

11. George, W. J., R. D. Wilkerson, and P. J. Kadowitz. 1973. Influence of acetylcholine on contractile force and cyclic nucleotide levels in the isolated perfused rat heart. J. Pharmacol. Exp. Ther. 184:228-235.

12. Watanabe, A. M., and J. R. Besch. 1975. Interaction between cyclic adenosine monophosphate and cyclic guanosine monophosphate in guinea pig ventricular myocardium. Circ. Res. 37:309-317.

13. Murad, F., Y. M. Chi, T. W. Rall, and E. W. Sutherland. 1962. Adenyly cyclase. III. The effect of catecholamines and choline esters on the formation of adenosine $3^{\prime}, 5^{\prime}$-phosphate by preparations from cardiac muscle and liver. $J$. Biol. Chem. 237:1233-1238.

14. Schmied, R., and M. Korth. 1990. Muscarinic receptor stimulation and cyclic AMP-dependent effects in guinea-pig ventricular myocardium. Br. J. Pharmacol. 99:401-407.

15. Loffelholz, K., and A. J. Pappano. 1985. The parasympathetic neuroeffector junction of the heart. Pharmacol. Rev. 37:1-24.

16. Hartzell, H. C., and R. Fischmeister. 1986. Opposite effects of cyclic GMP and cyclic AMP on $\mathrm{Ca}^{2+}$ current in single heart cells. Nature (Lond.). 323:273275.

17. Mery, P. F., S. M. Lohmann, U. Walter, and R. Fischmeister. 1991. Ca ${ }^{2+}$ current is regulated by cGMP-dependent protein kinase in mammalian cardiac myocytes. Proc. Natl. Acad. Sci. USA. 88:1197-1201.

18. McMahon, T. J., and P. J. Kadowitz. 1992. Methylene blue inhibits neurogenic cholinergic vasodilator responses in the pulmonary vascular bed of the cat Am. J. Physiol. 263:L575-L584.

19. Broten, T. P., J. K. Miyashiro, S. Moncada, and E. O. Feigl. 1992. Role of endothelium-derived relaxing factor in parasympathetic coronary vasodilation. Am. J. Physiol. 262:H1579-H1584.

20. Li, C. G., and M. J. Rand. 1990. Nitric oxide and vasoactive intestinal polypeptide mediate non-adrenergic, non-cholinergic inhibitory transmission to smooth muscle of the rat gastric fundus. Eur. J. Pharmacol. 191:303-309.

21. Gibson, A., S. Mirzazadeh, A. J. Hobbs, and P. K. Moore. 1990. L$N^{\mathrm{G}}$-monomethyl arginine and $\mathrm{L}-N^{\mathrm{G}}$-nitro arginine inhibit non-adrenergic, noncholinergic relaxation of the mouse anococcygeus muscle. Br. J. Pharmacol. 99:602-606

22. McKirdy, H. C., M. L. McKirdy, M. J. Lewis, and R. W. Marshall. 1992. Evidence for involvement of nitric oxide in the non-adrenergic non-cholinergic
(NANC) relaxation of human lower oesophageal sphincter muscle strips. Exp. Physiol. 77:509-511.

23. Fajfer, J., W. J. Aronson, P. A. Bush, F. J. Dorey, and L. J. Ignarro. 1992. Nitric oxide as a mediator of relaxation of the corpus cavernosum in response to nonadrenergic, noncholinergic neurotransmission. N. Engl. J. Med. 326:90-94.

24. Parent, R., M. Al-Obaidi, and M. Lavallee. 1993. Nitric oxide formation contributes to $\beta$-adrenergic dilation of resistance coronary vessels in conscious dogs. Circ. Res. 73:241-251.

25. Bush, P. A., N. E. Gonzalez, J. M. Griscavage, and L. J. Ignarro. 1992. Nitric oxide synthase from cerebellum catalyzes the formation of equimolar quantities of nitric oxide and citrulline from L-arginine. Biochem. Biophys. Res. Com mun. 185:960-966.

26. Grossman, W. 1991. Evaluation of systolic and diastolic function of the myocardium. In Cardiac Catheterization, Angiography and Intervention. W. Grossman and D. S. Baim, editors. Lea \& Febiger, Malvern, PA 319-339.

27. Colucci, W. S., A. R. Denniss, G. F. Leatherman, R. J. Quigg, P. L. Ludmer, J. D. Marsh, and D. F. Gauthier. 1988. Intracoronary infusion of dobutamine to patients with and without severe congestive heart failure: dose-response relationships, correlation with circulating catecholamines, and effect of phosphodiesterase inhibition. J. Clin. Invest. 81:1103-1110.

28. Wallenstein, S., C. L. Zucker, and J. L. Fleiss. 1980. Some statistical methods useful in circulation research. Circ. Res. 47:1-9.

29. Shulz, R., E. Nava, and S. Moncada. 1992. Induction and potential biologic relevance of a $\mathrm{Ca}^{2+}$-independent nitric oxide synthase in the myocardium. $\mathrm{Br}$. J Pharmacol. 105:575-580.

30. Brady, A. J. B., J. B. Warren, P. A. Poole-Wilson, T. J. Williams, and S. E. Harding. 1993. Nitric oxide attenuates cardiac myocyte contraction. Am. J. Physiol. 265:H176-H186.

31. Paulus, W. J., P. J. Vantrimpont, and A. M. Shah. 1994. Acute effects of nitric oxide on left ventricular relaxation and diastolic distensibility in humans: assessment by bicoronary sodium nitroprusside infusion. Circulation. 89:20702078

32. Buxton, I. L. O., D. J. Cheek, D. Eckman, D. P. Westfall, K. M. Sanders, and K. D. Keef. 1993. $N^{\mathrm{G}}$-nitro-L-arginine methyl ester and other alkyl esters of arginine are muscarinic receptor antagonists. Circ. Res. 72:387-395.

33. Rees, D. D., R. J. J. Palmer, H. F. Hodson, and S. Moncada. 1989. A specific inhibitor of nitric oxide formation from $L$-arginine attenuates endotheliumdependent relaxation. Br. J. Pharmacol. 96:418-424.

34. Rees, D. D., R. M. J. Palmer, R. Schulz, H. F. Hodson, and S. Moncada 1990. Characterization of three inhibitors of endothelial nitric oxide synthase in vitro and in vivo. Br. J. Pharmacol. 101:746-752

35. Krause, E. G., W. Halle, and A. Wollenberg. 1972. Effect of dibutyry cyclic GMP on cultured beating rat heart cells. Adv. Cyclic Nucleotide Res. 1:301305.

36. Shah, A. M., H. Spurgeon, S. J. Sollott, A. Talo, and E. G. Lakatta 1994. 8-bromo-cGMP reduces the myofilament response to $\mathrm{Ca}^{2+}$ in intact cardiac myocytes. Circ. Res. 74:970-978.

37. Shah, A. M., M. J. Lewis, and A. H. Henderson. 1991. Effects of 8 bromo-cyclic GMP on contraction and on inotropic response of ferret cardiac muscle. J. Mol. Cell. Cardiol. 23:55-64.

38. Mery, P.-F., C. Pavoine, L. Belhassen, F. Pecker, and R. Fischmeister 1993. Nitric oxide regulates cardiac $\mathrm{Ca}^{2+}$ current. Involvement of cGMP-inhibited and cGMP-stimulated phosphodiesterases through guanylyl cyclase activation. $J$. Biol. Chem. 268:26286-26295.

39. Han, X., Y. Shimoni, and W. R. Giles. 1994. An obligatory role for nitric oxide in autonomic control of mammalian heart rate. J. Physiol. 476:309-314.

40. Balligand, J.-L., D. Ungureanu-Longrois, W. W. Simmons, D. Pimental T. A. Malinski, M. Kapturczak, Z. Taha, C. J. Lowenstein, A. J. Davidoff, R. A Kelly, T. W. Smith, and T. Michel. 1994. Cytokine-inducible nitric oxide synthase (iNOS) expression in cardiac myocytes: characterization and regulation of iNOS expression and detection of iNOS activity in single cardiac myocytes in vitro. $J$. Biol. Chem. 269:27580-27588.

41. Balligand, J.-L., D. Ungureanu-Longrois, W. W. Simmons, L. Kobzik C. J. Lowenstein, S. Lamas, R. A. Kelly, T. W. Smith, and T. Michel. 1994 Induction of NO synthase in rat cardiac microvascular endothelial cells: IL-1 $\beta$ and IFN $\gamma$ promote transcription of an endothelial iNOS. Am. J. Physiol. In press.

42. Klimaschewski, L., W. Kummer, B. Mayer, J. Y. Couraud, U. Preissler B. Philippin, and C. Heym. 1992. Nitric oxide synthase in cardiac nerve fibers and neurons of rat and guinea pig heart. Circ. Res. 71:1533-1537.

43. Balligand, J.-L., D. Ungureanu, R. A. Kelly, L. Kobzik, D. Pimental, T. Michel, and T. W. Smith. 1993. Abnormal contractile function due to induction of nitric oxide synthesis in rat cardiac myocytes follows exposure to activated macrophage-conditioned medium. J. Clin. Invest. 91:2314-2319.

44. Brady, A. J. B., P. A. Poole-Wilson, S. E. Harding, and J. B. Warren 1992. Nitric oxide production within cardiac myocytes reduces their contractility in endotoxemia. Am. J. Physiol. 263:H1963-H1966. 